\title{
Italique
}

Poésie italienne de la Renaissance

VI $\mid 2003$

Varia

\section{La Pléiade entre Bembo et l'Arioste}

\section{André Gendre}

\section{OpenEdition}

\section{Journals}

Édition électronique

URL : http://journals.openedition.org/italique/134

DOI : $10.4000 /$ italique.134

ISSN : 1663-4438

\section{Éditeur}

Librairie Droz

\section{Édition imprimée}

Date de publication : 31 décembre 2003

Pagination : 7-36

ISBN : 2-600-00893-4

ISSN : 1423-3983

Référence électronique

André Gendre, «La Pléiade entre Bembo et l'Arioste », Italique [En ligne], VI | 2003, mis en ligne le 05 octobre 2009, consulté le 01 mai 2019. URL : http://journals.openedition.org/italique/134 ; DOI : 10.4000/italique.134 


$$
\begin{gathered}
\text { André Gendre } \\
\text { LA P LÉ I A D E } \\
\text { ENTRE B EMB O E T L'A I I T T E }
\end{gathered}
$$




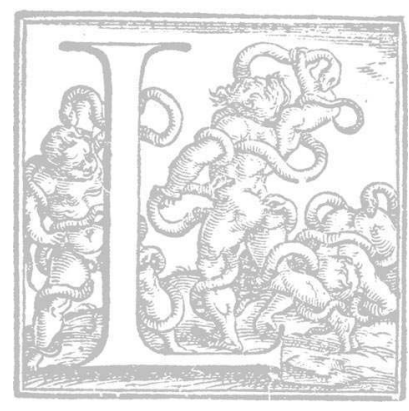

'Auteur de cette étude est un "seiziémiste" non italianisant. Sa seule justification est d'avoir beaucoup suivi, chez les poìtes de la Pléiade, le devenir de l'inspiration pétrarquiste, "quattrocentiste" et "cinquecentiste". Ce n'est pas toujours un auteur qu'on imite, mais un passage qui a paru intéressant, comme un peintre découvre un sujet à reproduire dans la nature ou dans une forme qui le frappe. L'imitation, en matière de poésie amoureuse par exemple, n'implique pas toujours la reconnaissance, fût-elle éphémère, d'une doctrine philosophique, d'une expérience commune, d'une affinité de sentiments; elle est souvent comme un masque du sens qu'on emprunte pour le rendre ensuite. Elle correspond aussi à une séduction formelle momentanée. Ces pratiques aléatoires paraissent condamner la recherche d'une influence très particulière exercée sur nos poètes. Il est vrai que la Pléiade ne choisit souvent Bembo ou l'Arioste que pour leurs lieux communs pétrarquistes. ' Mais ces modèles sont trop grands poètes pour ne pas déterminer plus spécifiquement ceux qu'ils inspirent.

\section{La sérénité néo-platonicienne de Bembo}

Ce poète requiert surtout l'attention de Du Bellay, Ronsard et Baï. Singulièrement, on trouve peu de traces d'emprunts chez. Tyard, Belleau ou Jodelle. Il faut sans doute envisager Bembo comme l'un des plus grands relais du pétrarquisme à l'orée du XVI siècle italien. Avec lui, la poésie amoureuse conserve le style élevé que deux siècles auparavant le grand Toscan lui a conféré et que certains continuateurs du Quattrocento lui ont conservé. Néanmoins, le développement du néo-platonisme ficinien a modifié l'horizon amoureux. Le salut ne s'opère plus par l'intercession de Laure devenue progressivement la Vierge, mais par cette élévation divine à laquelle donne accès la femme aimée. Bembo détermine chez les poètes de la Pléiade, Ronsard en particulier, une inspiration marquée par le néo-platonisme ou par les réseaux imaginaires de la sérénité qui s'y trouvent liés. Il ne faut jamais perdre de vue le sonnet 30 des Rime, que la Pléiade n'a pas imité, à ma connaissance, mais qui atteste bien l'équilibre de Bembo. À partir du topos ressassé du «dolce-amaro»," le poète imagine un dialogue entre Amour et l'amant souffrant. Pourquoi faut-il, pense celui-ci, que deux sentiments contraires soient si souvent associés? La réponse $d u$ dieu ressortit à un équilibre actif qu'aucun autre n'a exprimé avec cette force: 
Confusi, mentre l'un con l'altro male contende e scemal di sua forza in parte, quel, che v'ancideria per sé, v'aita.

(Rime 30, 1 2-14) ${ }^{3}$

Dans le sonnet 38 des Rime, l'amoureux connaît la situation la plus enviable qui soit: il est à la fois déterminé dans son amour par la haute Raison qui gouverne le monde et choisi comme l'exemple même, l'exemple privilégié, avec celle qu'il aime, des rapports que cette haute Raison entretient avec le monde:

L'alta cagion, che da principio diede

a le cose create ordine e stato,

dispose ch'io v'amassi e dielmi in fato,

per far di sé col mondo exempio e fede

(Rime 38, I-4)

L'attrait exercé par la femme désirée équivaut à la seule contemplation, qui est une récompense suffisante pour tout travail de la passion. Aussi l'amoureux se tourne-t-il vers sa belle comme l'héliotrope vers le soleil. ${ }^{4}$ Ronsard est à ce point séduit par ce sonnet qu'il l'imite presque littéralement. À peine se permet-il quelques modestes changements. La Raison divine continue de gouverner le monde et de déterminer l'amant qui se perd dans la contemplation et y trouve son entière satisfaction; simplement, Ronsard ne dit pas que le couple est exemplaire de l'harmonie voulue par la Raison; il souligne plutôt l'importance du monde construit sur le modèle de l'Idée et qui devient un temple:

Celuy qui fit le monde façonné

Sur le compas de son parfait exemple,

Le couronnant des voustes de son temple,

M'a par destin ton esclave ordonné

$$
\text { (Les Amours I 7 I, I-4) }
$$

Bembo représente pour l'imaginaire ronsardien un pôle de paix et de grandeur, qui est désiré, soubaité, sans être toujours atteint. Ainsi en est-il de la chute du sonnet Ios des Amours. Belle image de l'oisean qui vole et revole sur le lieu où il a trouvé sa nourriture. Pour Bembo, cette nourriture est le regard serein de son amante, sa beauté, sa parole sage. L'oiseau est l'âme tourmentée que la belle vision rassérène:

solo di voi pensando si tranquilla

in me la tempestosa mente [...]

[... 
perch'ella, com'augel, ch'a parte vole ond'ha suo cibo, a lor sempre ritorna con l'ali del desio veloci e calde.

(Rime 82, 5-6, I 2-14)

Ronsard parvient à cette chute par un tout autre chemin. Ce n'est pas le regard serein qui est invoqué ("Caro sguardo sereno»), mais plusieurs parties du corps: l'ail, le sourcil et le front étoilé; la gorge, le tétin et le sein. Ces attraits éveillent un désir plus âpre et transforment l'oiseau désirant de Bembo en un rude prédateur:

Comme un oyseau, qui ne peult sejourner, Sans revoler, tourner, \& retourner,

Aux bordz congneuz pour y trouver sa proye.

Même contraste de la sérénité détachée et de l'inquiétude dans un emprunt que l'on n'a jamais signalé jusqu'ici. On admire souvent le très beau sonnet adressé par Ronsard à Baïf, où le poète évoque sa rêverie devant un paysage qu'il aime tant, les bords du Loir:

Icy, Bayf, où le mont de Sabut

Charge de vins son espaulle féconde,

Pensif je voy la fuite vagabonde

Du Loyr qui traisne à la mer son tribut

(Les Amours I 33, 5-8)

Ces beaux vers sont transposés de Bembo s'adressant à son ami Tommaso Giustinian:

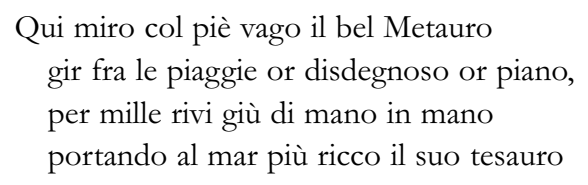

(Rime 24, 5-8)

Le poète italien tire de sa contemplation rêveuse du paysage sérénité et détachement: «assai tranquillo e riposato vivo, / sprezzando'l mondo, e molto più me stesso» (Rime 24, I3-I4). Le poète français, quant à lui, s'agite dans une nature romantique: "Ores un antre, or un desert sawvage, / Ore me plaist le segret d'un rivage, / Pour essayer de tromper mon ennuy» (Les Amours I33, 
9-II). Du conflit entre le pouvoir et la volonté naît chez Bembo (Rime I36) une vision haute et sereine de l'écriture poétique; Ronsard (Les Amours 64) la reprend. Tous deux partent de Pétrarque dont ils corrigent la modestie. En effet, celui-ci se contentait de séduire l'Italie, ne se trouvant pas le pouvoir de rayonner au-delà. Bembo et Ronsard ont des visées plus ambitieuses, le premier celle de faire resplendir dans la nuit des temps futurs la «vraie et douce image» de la femme aimée, le second de projeter dans l'espace céleste «sus l'aisle de $[\mathrm{s}]$ a rime» le nom de Cassandre.

La sérénité de Bembo n'est pas sans affecter le domaine du songe. Ronsard doit à son modèle italien deux sonnets sur ce thème, Baïf un seul. Chez le poète italien (Rime 89), le songe est loué comme un moment heureux et paradisiaque où l'amour recherché et déclaré reçoit une réponse favorable. Aucune lasciveté particulière ne vient marquer le sonnet 89 qui résonne, jusqu'à son premier tercet, du bonbeur d'un accord spirituel (le second tercet est réservé au réveil cruel). C'est ici que le travail de la contamination se fait jour. Le bouillant Vendômois ne saurait s'en tenir à un rêve contrôlé. Si Perottino, dans les Azolains, allait jusqu'à penser que les songes peuvent épurer les désirs, le jaillissement libidinal interdit à Ronsard pareille maîtrise. Sur le canevas élaboré par Bembo, le poète français va butiner des audaces chez. les néo-latins, que l'on sait orfêres en la matière. Mais sa contamination inclut Bembo lui-même. Comme la chute du «songe» imité lui paraissait prosä̈que (selon toute vraisemblance), il emprunte celle du songe contigu, caractéristique de la manière finement pittoresque de son modèle. Après le songe, lit-on, vient le sommeil et la belle disparait:

Gìosene appresso il sonno, ed ella, inseme co' miei diletti e con la notte intorno, quasi nebbia sparì, che 'l vento sgombre.

(Rime 90, I 2-I 4)

Ronsard ne se montre pas indigne de ce congé poétique:

Et tu me fuis au meillieu de mon bien, Comme l'esclair qui se finist en rien, Ou comme au vent s'esvanouit la nuë.

(Les Amours 29, I 2-I 4)

Dans l'autre «songe» contigu de Bembo (Rime 88), le poète demande à son visiteur par quelle porte (celle de corne ou d'ivoire) il s'est glissé du ciel et il le remercie d'être le seul remède à son mal méchant. Si Ronsard suit avec une certaine liberté ce poème, Baïf s'y attache à la lettre et le traduit quasiment 
(L'Amour de Francine II IOI). Mais traduire, c'est quelquefois créer. On peut surprendre Baïf dans un trait qui lui est propre: Bembo disait en conclusion: «fammi talor di quel piacer sentire, / che senza te non spero sentir mai» (Rime 88, I3-I4). Baïf dira: «Et me fay quelque fois cette joye sentir, I Que d'ailleurs que de toy me promettre je n'oses. Le poète français ajoute ici à son modèle une marque qui lui est propre et qu'on retrowve souvent chez. lui: une pratique de l'introspection et la volonté de se connaître. En telle matière, «me promettre je n'ose» en dit plus, dans la belle inversion d'un alexandrin balancé, que «non spero sentir mai». Du Bellay s'inspire de la même pièce pour nous offrir le sonnet le plus sensuel de l'Olive: Le fort sommeil, que celeste on doibt croyre (s. I4). Du Bellay répond à la question de Bembo en affirmant que le songe s'est introduit chez lui par la porte d'vivoire (la voie des songes trompeurs). Comme Ronsard, il emprunte aux poètes néo-latins, à Jean Second en particulier, ses traits érotiques: les «lasses mouëlles》 et la comparaison de l'embrassement des ormes par le «sep lascif». Du Bellay ne prie pas le songe de revenir - ce que faisait Bembo -, mais il retourne à son début, dans une forme cyclique très poétique: "Quand le reveil, de mon ayse envieux, / Du doulx sommeil a les portes decloses».

Loin des hypotyposes néo-platoniciennes de Dieu, loin du songe, loin de l'amour serein de la beauté, on ne s'étonnera pas que le seul Du Bellay, à la fin de l'Olive (s. 109), ait emprunté à Bembo un sonnet de la pénitence chrétienne ou, pour le moins, le huitain de ce qui est une prière de repentance (Rime I64, I-8). Comme Bembo, Du Bellay oppose son biver à venir au printemps des passions qui détournent de Dieu. Chez les deux poètes, le repentir est confiant, puisque la perspective de la mauvaise saison conduit le premier à une piété pleine et solide («piena e salda»), ce que le second transpose, parlant à Dieu, en une «celeste envie» qui fera «mieux gồter la donceur de tes loix»».

\section{Le pittoresque de Bembo}

À côté de la sérénité amoureuse, qui a son origine dans une conception néo-platonicienne des passions, Bembo inspire à la Pléiade ce qu'on pourrait appeler un pittoresque maniériste. Ce pittoresque est avant tout animalier. Pétrarque avait repris aux poètes courtois le motif de l'oiseau, en particulier celui du rossignol (Rvf. 3II et 353). L'amoureux trouve dans cet habitant des bois solitaires un alter ego, mais un alter ego qui ne partage pas complètement son malheur. Pour Pétrarque, la compagne de l'oiseau est en vie, malgré son absence, alors que Laure a disparu à jamais. Cette antithèse se transforme chez Bembo, où l'oiseau, séparé momentanément de sa belle, la retrouvera le 
jour même peut-être, tandis que l'amoureux se voit soumis à un délai incertain et lointain (Rime 48, 5-8). Ce même amoureux, chez Bembo également, charge le rossignol d'un message pour sa belle inflexible (Rime 56, v. 22 sqq.). Ces détails se retrouvent, parmi beaucoup d'autres venus d'ailleurs, dans deux pièces des Continuations (43 et Nouvelle Continuation des Amours, sonnet $\mathrm{O}$ ma belle maitresse) et dans un sonnet de Baïf (L'Amour de Francine I, 25). C'est Bembo également qui inspire à Ronsard un sonnet pratiquement traduit où le cour, qui a quitté la poitrine de l'amoureux, se prend dans les beaux cheveux de l'aimée:

volò subitamente in quel dolce oro, e fe' come augellin tra verde alloro, ch'a suo diletto va di ramo in ramo.

(Rime 9, 6-8)

Mon cuœur, helas, qu'en vain je r'appelle ore,

Vola dedans, ainsi qu'un jeune oyseau, Qui s'enfueillant dedans un arbrisseau, De branche en branche à son plaisir s'essore.

(Les Amours 177, 5-8)

A pittoresque, pittoresque et demi!

La capture de l'amoureuse ou de l'amoureux amène Bembo à peindre deux tableaux de chasse. D'abord celui de la poursuite vaine d'une bête sauvage qui s'est enfuie si légèrement que l'amoureux en a perdu la trace: "La fera, che scolpita nel cor tengo, / cosi l'avess'io viva entro le braccia» (Rime 94, I-2). Ronsard dira plus crûment: "Puissé-je avoir ceste Fére aussi vive / Entre mes bras, qu'elle est vive en mon cuœur» (Les Amours I29). Au sizain du sonnet, Ronsard se sépare de Bembo; alors que celui-ci continue de déplorer son impuissance à rattraper le bel animal, Ronsard lui adresse une prière: "Au moins escoute ... / Comme veneur je ne te poursuy pas». Dans l'autre scène de chasse, c'est l'amoureux qui est poursuivi et blessé à mort. Tout lecteur des textes renaissants se souvient du sonnet du chevreuil, tôt sorti de son bois au premier printemps, s'ébrouant joyeux et sans crainte, mais insidieusement touché par un trait meurtrier. ${ }^{6}$ Bembo nous donne ici l'un de ses plus beaux poèmes:

Sì come suol, poi che 'l verno aspro e rio

parte e dà loco a le stagion migliori, giovene cervo uscir col giorno fuori del solingo suo bosco almo natio,

(Rime 3, I-4) 
Ronsard suit de très près ce texte, reproduisant en détail la narration, adoptant la syntaxe jusque dans l'anacoluthe homérique du premier tercet; et pourtant, il poétise à sa manière ce pittoresque sylvestre:

Comme un Chevreuil, quand le printemps destruit

L'oyseux crystal de la morne gelée,

Pour mieulx brouster l'herbette emmielée

Hors de son boys avec l'Aube s'en fuit,

$$
\text { (Les Amours 49, I-4) }
$$

Le cristal immobile de la gelée sans vie: le vers est poétisé à frais nouveaux et très personnels! Dans L'Amour de Francine, Baïf reprend également ce sonnet et, comme Ronsard, il l'imite de très près. On ne s'étonnera pas que ses innovations soient essentiellement syntaxiques, car la recherche de la disposition est un des points forts de Baï:

Comme quand le printemps de sa robe plus belle

La terre parera, lors que l'yver depart,

La bische toute gaye à la lune s'en part

Hors de son bois aimé, qui son repos recele

$$
\text { (L'Amour de Francine II 9, I-4) }
$$

L'accumulation initiale, un peu rbétorique, finit par s'équilibrer dans des bémistiches bien balancés. Si l'on considère les serpents qui bérissent son visage, incorporons au pittoresque animalier celui de Méduse. On n'a point signalé encore cet emprunt, mais c'est à Bembo que Ronsard doit sa multiplication des effets «médusins»:?

Medusa, s'egli è ver che tu di noi facevi petra, assai fosti men dura di tal che m'arde, strugge, agghiaccia e 'ndura.

(Rime 86, I 2-I 4)

devient chez Ronsard:

Tout cela que lon dit d'une Meduse antique Au prix d'elle n'est rien que fable poëtique Meduse seulement tournoit l'homme en rocher, Mais cette-cy en-roche, en-glace, en-eaue, en-foue Ceus qui ozent sans peur de ses yeus approcher: Et si en les tuant vous diriez qu'el' se joue. 
La réécriture de Bembo équivaut pour Ronsard à une création verbale audacieuse.

Le même maniérisme pittoresque se retrouve dans un sonnet anquel les vœux en adynata conferent comme une allure surréaliste. Mais, sans le dire, on chante le retour de l'Âge d'or, évoqué par Virgile dans la quatrième églogue. Il s'agit pour Bembo de célébrer la naissance du fils de duc della Rovere et de Leonora Gonzaga; il s'agit pour Ronsard de célébrer la naissance de Henri de Bourbon, fils d'Antoine, souverain du Vendômois. L'béritier du duc, pas plus que le prince français, frère aîné du futur Henri IV encore à naître, ne vécurent longtemps; ils contredirent ainsi les soubaits de nos poètes. Bembo étage son décor sur trois plans: d'abord le soubait d'une contrée transformée:

Verdeggi a l'Appennin la fronte e 'l petto

d'odorate felici arabe fronde,

corra latte il Metauro e le sue sponde

copran smeraldi e rena d'oro il letto.

Puis la sérénité de l'espace sublunaire et des étoiles:

Taccian per l'aere i venti, e caldo o gelo, come pria, nol distempre, e tutti i lumi, che portan pace a noi, raccenda il cielo.

Enfin la métamorphose morale du monde:

D'alti pensieri, oneste e pure voglie, lodate arti, cortesi e bei costumi

si vesta il mondo, e mai non se ne spoglie.

(Rime 39, I-4, 9-I I et I 2-I 4)

Unifiant les plans - ou peu s'en faut - Ronsard s'en tient à un tableau d'ici-bas, laissant de côté l'équilibre des contraires et la paix des astres. Comme nous l'avons remarqué déjà, il est séduit par les visions sereines, mais il s'en distingue quelque peu:

Que Gastine ait tout le chef jaunissant

De maint citron \& mainte belle orenge,

Que toute odeur de toute terre estrange,

Aille par tout noz plaines remplissant.

Le Loyr soit laict, son rempart verdissant

En un tapis d'esmeraudes se change,

Et le sablon, qui dans Braye se range,

D'arenes d'or soit par tout blondissant. 
Pleuve le ciel des parfumz \& des roses,

Soyent des grands ventz les aleines encloses,

La mer soit calme, \& l'air plein de bon heur.

(Les Amours I 72, I-I I)

Un des aspects fréquents de l'imitation, et très bien vérifié ici, consiste à renchérir sur le modèle. Ronsard s'attache à la description des changements et en souligne le caractère inchoatif. Il soigne le détail de l'image qu'il n'est pas loin de saturer. Bembo était plus sensible à une hiérarchie des transformations. En termes généraux de critique littéraire, disons que les poètes de la Pléiade ont été séduits, chez. Bembo, poète amoureux, par deux registres majeurs: celui de la sérénité néo-platonicienne et celui d'un pittoresque finement maniériste. Mais nos poètes, qui étaient avec Scève les premiers de la Renaissance française à parcourir les vastes champs de l'imaginaire, cherchaient aussi la fantaisie libre et la sensualité à côté de l'ordre et de la finesse. Avec Serafino, Baldassare Olimpo et Tebaldeo, l'Arioste allait les leur apporter.

L'Arioste stimule l'imaginaire sensuel des poètes de la Pléiade

Ne pensons pas que l'Arioste inspire toujours à la Pléiade un registre d'emprunts très particulier, qui le distinguerait par exemple de Bembo. Les grands poètes du Cinquecento appartiennent à la mouvance pétrarquiste; proches du Toscan, ils inspirent des poèmes qu'on croirait venus du Canzoniere. ${ }^{8}$ C'est le cas des Rime de l'Arioste, écrites essentiellement avant l'Orlando Furioso. Du Bellay est souvent séduit par ce recueil. Des cheveux d'or qui sont des liens, un feu d'Amour qui brûle, mais que toutefois l'on aime;" un Archer aveugle et donc "mal avisés, qui blesse l'amant sans toucher la belle; ${ }^{\text {厂 }}$ une impuissance à chanter dignement les perfections de la femme aimée; ${ }^{\mathrm{I}}$ le mal et la douleur d'amour considérés malgré tout comme des biens, comme un témoignage aussi qui ne devrait pas être rejeté: ${ }^{12}$ voilà quelques exemples d'imitations intéressantes dans le détail, mais sans grande signification spécifique.

Mais il est un autre Arioste. Au début de son Der Dichter und das Phantasieren, ${ }^{13}$ Freud fait allusion à cette réflexion du cardinal Hippolyte d'Este après la parution de l'Orlando Furioso: "Dove avete trovato, messer Lodovico, tante corbellerie?»), "Où donc avez-vous trouvé, messire Louis, tant de sottises?" ou plutôt "tant de bourdes". Au XVT siècle, ce dernier terme ne signifiait pas "bévue", "gaffe", mais "bistoire inventée - peut-être pour tromper -, à coup sûr, pour amuser". Ronsard dit dans ce sens, dans la VII Folastrie: "Assez vrayment on ne revere / Les divines bourdes d'Homere» 
(I-2). L'Orlando Furioso fourmille de bourdes, le cardinal d'Este ne se trompait pas. Ce vaste poème n'est qu'entrecroisements d'bistoires différentes, variations de tons et de propos, liberté, avant tout sensuelle, de l'imaginaire. ${ }^{\mathrm{I}}$ Les poètes de la Pléiade sont tous à la recherche de cette liberté, même les plus discrets comme Du Bellay. L'Orlando Furioso et aussi quelques sonnets des Rime fournissent à point nommé images et récits séduisants. Voici Du Bellay suivant l'Arioste dans la prison d'amour la plus pétrarquiste qui soit, sinon que "Mile doulx motz,... Mil" doulx baisers»" ${ }^{15}$ y retiennent charmé tout amoureux. La prétérition peut être une brèche dans laquelle se glisse la sensualité. C'est ainsi que le sonnet Altri loderà il viso (Rime 20) s'ouvre sur un éloge de la chevelure, du sein et du flanc d'vivoire, des beaux yeux de la femme aimée..., prétérition qui dure le temps d'un quatrain: 'il appartient à un autre de les chanter; quant à moi...'. Le reste du poème est précisément consacré à un éloge spirituel. Les poètes de la Pléiade mettent l'accent sur la sensualité en prolongeant la prétérition; Du Bellay le fait pour ainsi dire chastement. ${ }^{16}$ Cheveux, sourcils, corail des lèvres, teint, lys et roses (métaphore générale): le corps tient plus de place que l'esprit. L'intensité sensuelle du portrait est encore plus forte dans le sonnet 49 des Amours (I553) de Ronsard:

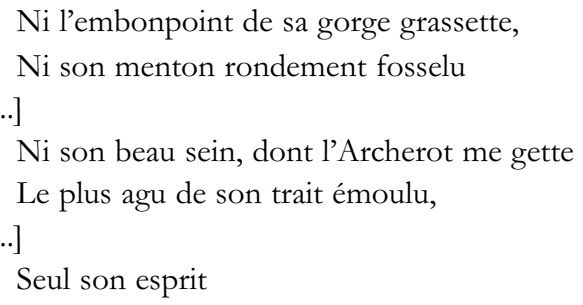

(Les Amours 49, 3-4, 7-8, I 2)

dit entre autres un poète également séduit par les appas charnels et la perfection spirituelle. Autre prétérition antithétique, celle qui est empruntée au sonnet bien connu Madonna, sète bella (Rime 30). L'Arioste y vante, chez sa belle, un certain nombre d'attraits physiques attendus (sans oublier «di terso alabastro il collo e il seno»), mais finit par affirmer que ces qualités n'égalent en rien la force de sa foi. Cette pièce donne lieu à quatre réecritures: Du Bellay suit très littéralement la pièce italienne, sans beaucoup d'invention (L'Olive 7). Tyard équilibre avec beaucoup de sûreté et de liberté la part des charmes féminins et celle de sa foi (Erreurs amoureuses I, 3). Ronsard retient le canevas de l'Arioste, c'est-à-dire l'énoncé des différentes parties du corps, mais il exécute autour de chacune d'elles des volutes personnelles; par exemple: 
De neige \& feu s'embellit son visage,

Pour qui Juppin reprendroyt le plumage,

Ore d'un Cygne, or le poyl d'un toreau.

$$
\text { (Les Amours i 56, 6-8) }
$$

Baïf prend aussi ses libertés et se distingue par des effets de répétitions et la disposition syntaxique des éléments répétés:

Tresbelles sont ses mains, et tres-beaus sont ses bras:

Et sa gorge est tres-belle, et tres-beau son beau sein:

Tout ce qu'en elle on voit est fort emerveillable,

Et ses beautés n'ont rien de semblable icy bas:

Elle a tout admirable, elle a tout plus qu'humain:

Si diray-je ma foy beaucoup plus admirable.

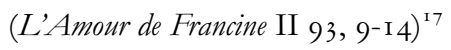

En inspirant presque littéralement le buitain du sonnet de Ronsard $\mathrm{O}$ de Nepenthe, \& de lyesse pleine (Les Amours 102), l'Arioste offre à son imitateur un texte audacieux, qui célèbre la «cameretta cara», la «chambrette beureuse» où l'amour s'est accompli, O sicuro, secreto (Rime 8). Ronsard sait aussi ajouter la sensualité quand il ne la trouve pas chez. l'Arioste. Ernesta Caldarini nous a révélé, dans le sonnet io des Rime, Felice stella, ${ }^{18}$ une source jusqu'alors inconnue du sonnet des Amours: Heureuse fut l'estoille fortunée (108). Ronsard suit presque littéralement la progression du bonheur: 'Felice stella..., heureuse l'étoile qui imprima son influence à la naissance de la belle, felice chiostro..., beureux le berceau qui la porta, beureux le sein qui la nourrit, beureux le ventre qui la conçut, heureux les champs qui la virent naitre'. L'Arioste termine sur une progression qui sert de chute au sonnet: non plus felice, mais beato:

Ma beato chi vita da quel prende, ove 'l bel lume morte disacerba, ch'un molto giova e l'altro poco offende.

$$
\text { (Rime 10, I 2-14) }{ }^{19}
$$

Dans ce dernier tercet, Ronsard, plus lascif, abandonne l'Arioste pour se souvenir de Marot et de son blason du «beau Tetin»:20

Heureux le filz dont grosse elle sera,

Mais plus heureux celuy qui la fera

Et femme \& mere, en lieu d'une pucelle.

$$
\text { (Les Amours I08, I 2-I4) }
$$


La réécriture peut-être la plus remarquable de l'A iroste par Ronsard se trouve dans le sonnet des Amours: Entre tes bras, impatient Roger (92), au buitain surtout: cueillette dans le plus beau jardin de l'Arioste, puis un miel concentré dans sa pure essence. Nous sommes ici dans une réussite absolue de l'imitation qui réunit le même et l'autre. Il s'agit de l'épisode de Roger au château d'Alcine; nous passons donc des Rime à l'Orlando Furioso. Suivons, chez. l'Arioste, la soirée de Roger. Arrivé dans le palais, il est séduit sur-le-champ par le charme puissant de la magicienne. Après un dîner somptueux, les amants décident de se retrouver pour passer la nuit ensemble. Roger regagne sa chambre, seul: il reçoit encore une collation de bons vins et de douceurs. Installé dans son lit, il dresse l'oreille en espérant entendre le pas de sa belle. C'est elle? Non. Roger compte mentalement le nombre de pas qui le séparent de la chambre d'Alcine. L'attente se prolonge. Enfin, la belle se met lentement en mouvement et franchit le seuil de Roger:

Or sino agli occhi ben nuota nel golfo de le delizie e de le cose belle: salta del letto, e in braccio la raccoglie, né può tanto aspettar ch'ella si spoglie;

ben che né gonna né faldiglia avesse; che venne avolta in un leggier zendado che sopra una camicia ella si messe, bianca e suttil nel più escellente grado. Come Ruggiero abbracciò lei, gli cesse il manto; e restò il vel suttile e rado, che non copria dinanzi né di dietro, più che le rose $\mathrm{o}$ i gigli un chiaro vetro.

(Orlando Furioso vir 27, 5-8 et 28)

Elle a donc recouvert d'un manteau sa chemise de soie; mais soudain, ce manteau glisse et la gaze si fine qu'elle ne cache rien ressemble à un verre limpide qui, en les recouvrant, voudrait dissimuler une rose ou un lys. Les amants s'étreignent plus fort que le lierre n'embrasse la plante qui le soutient, ils cueillent bouche à bouche tous les parfums d'Orient. Chez. Ronsard, l'épisode tient essentiellement en huit vers:

Entre tes bras, impatient Roger,

Pipé du fard de magicque cautelle,

Pour refroydir ta chaleur immortelle,

Au soyr bien tard Alcine vint loger.

Opiniatre à ton feu soulager,

Ore planant, ore nouant sus elle, 
Dedans le gué d'une beaulté si belle,

Toute une nuit tu apris à nager.

$$
\text { (Les Amours 92, I-8) }
$$

Tout y est: la narration, le désir retardé et aiguisé par l'attente, le plaisir de l'étreinte comparé à l'immersion dans les flots (image fusionnelle). Mais tout s'y change aussi. L'attente devient syntaxique: inversion initiale de Entre tes bras et apparition du verbe principal trois vers plus bas, retardé à dessein. Au centre, les deux circonstances: la tromperie, exprimée par des mots auxquels le temps a mis une patine étrange (fard pour "duperie" et cautelle pour "ruse"; en effet Alcine est fondamentalement une sorcière) et le soulagement d'une passion à laquelle Ronsard confere comme une grandeur divine. Le second quatrain traduit dans une autre langue la marque érotique de l'Arioste: l'attente de nouveau, avec une série d'appositions préposées, les mouvements des amants discrètement évoqués sous le couvert d'une leçon de natation (tout cela est une métamorphose du golfo italien) et cette heureuse trowvaille du guépar où se marque l'amour salvateur.

Sans céder à une généralisation facile, on peut dire que l'Arioste a tracé pour Ronsard le chemin d'une expression sensuelle d'autant plus intense qu'elle est retenue.

\section{L'Arioste et le portrait érotique}

Mais la marque de l'Arioste sur la Pléiade peut se définir de façon plus précise encore. La sensualité prend forme dans le portrait. Celui d'Alcine, au chant VII (II-I6), et celui d'Olympie, au chant XI (67-7I) de l'Orlando Furioso, ont exercé chez. les poètes français une séduction si grande que plusieurs d'entre eux ont pensé que l'intérêt de l'Arioste se réduisait à onze octaves. Par ailleurs, la topique du portrait féminin n'est pas sortie tout armée du cerveau de notre poète. Le canon médiéval prescrivait une énumération de baut en bas et un choix de métaphores pour les parties les plus nobles. Ces métaphores appartenaient à des registres fixes: celui des fleurs (roses ou lys), celui des pierres précieuses. Pétrarque exerça son influence sur le schéma médiéval en réduisant le nombre de mentions à quelques parties choisies du visage, auxquelles s'ajoute épisodiquement telle autre partie du corps isolé; en intensifiant l'usage des métaphores, en se limitant aux trois couleurs jaune, rouge et blanche (avec une exception pour le noir des cils et l'azur des yeux) et en affectant au rouge la métaphore de la rose, au jaune celle de l'or et de l'ambre. S'élaborent ainsi ce que G. Pozzi appelle avec une certaine pertinence le canon bref. Mais, chez Boccace, puis an Quattrocento et an Cinquecento, le 
canon s'allonge en incluant des parties du visage rejetées par Pétrarque et en dépassant les frontières de la tête. C'est ainsi que Boccace, dans la Teseida (XII, 53-63, portrait d'Emilia), Pulci, dans Morgante (XV, 99-I04, portrait d'Antea) et Politien, dans ses Stanze (I, 42-46, portrait de Simonetta), inspirent très certainement l'Arioste. Dans la littérature comme dans les beaux-arts, la sensualité naît d'une description corporelle minutieuse; l'intérêt même pour les détails témoigne d'une liberté que l'esprit de la Renaissance encourage. $^{2 \mathrm{I}}$

Les portraits d'Alcine et d'Olympie se distinguent essentiellement par ce qu'on pourrait appeler l'bypotypose picturale, par le mouvement, qui vient animer ce qui était description statique, et par une sensualité raffinée, mais exprimée avec une certaine distance. Sur cette distance et à propos des deux portraits auxquels il consacre une étude chronologique très pertinente, $P$. Larivaille émet cette conclusion: "La déception de l'attente de l'auditoire et des lecteurs à laquelle il [l'Arioste] vise de façon pratiquement invariable, n'est au fond qu'un bel exemple de plus de cette fameuse ironie qui régit de bout en bout les rapports de l'Arioste non seulement avec la matière de son poème, mais avec son publicis. ${ }^{22}$

L'hypotypose picturale (ou plus généralement l'bypotypose inspirée par les beaux-arts). Le corps d'Alcine atteint aux meilleures représentations que les peintres pourraient en faire (VII, II); ses yeux se voient sous deux arches noires, et au-dessous d'eux le nez descend d'une façon si parfaite qu'elle dissuade toute jalousie (VII, I2). Les bras montrent leurs belles proportions (VII, I5). Les flancs, les hanches et le ventre plat semblent faits au tour comme les cuisses blanches paraissent l'cuvre de Phidias (XI, 69); si Olympie était née à Crotone, Zeuxis n'aurait pas en besoin de prendre plusieurs femmes pour modèles: elle représente à elle seule la perfection (XI, $7 I$ ). Le mouvement. ${ }^{23}$ C'est peut-être le trait majeur qui distingue l'Arioste. La série des beautés se décline selon un paradigme uniforme, mais le statisme de l'énumération se voit compensé par plusieurs mouvements. Devant les deux portraits d'Alcine et d'Olympie, Amour se meut: il vole, il joue et décharge son carquois ou bien il allume son dard dans le flambeau des yeux, puis le rafraîchit à la source qui coule de ces mêmes yeux, car Olympie pleure encore des frayeurs que l'Orque lui a inspirées; Amour ressemble à un rossignol qui prend ses ébats dans un arbre vert. Au cœur du portrait lui-même, le mouvement affecte les seins qui s'animent comme un doux courant suscité par le zéphyr ou qui voient se creuser un espace comme se marque une vallée entre deux monts que la neige abandonne au printemps. La sensualité. Elle naît de l'attention particulière accordée au corps, au point de vue qui inclut la rareté, l'inhabituel, voire l'étrange. L'Arioste se soucie des formes: le front d'ivoire se termine par un ovale gracieux (VII, II), les bras montrent leurs belles proportions, la main 
s'allonge, étroite; aucune veine n'y saille (VII, IS). Les flancs sont rebondis, mais le ventre est plat, plus égal qu'un miroir (XI, 69), etc. Le corps se transforme en la quintessence d'un objet précieux. En effet, on ne trouve pas d'or aussi brillant que les nouds des blonds cheveux (VII, II), les dents deviennent des perles (VII, I3), les seins paraissent deux pommes vertes, mais sont en réalité (!) un ferme ivoire (VII, I4). Selon le point de vue d'une natura naturata, les joues sont des roses, le cou de la neige (VII, I4), la gorge du lait (VII, I4); le corps fait partie intégrante d'une topographie: sous le nez, la bouche est peinte entre deux petites vallées (VII, I3) ou les seins en creusent une autre, comme on vient de le voir (XI, 68). Le corps participe des saisons et de la météorologie, comme le visage d'Olympie, encore monillé de larmes, ressemble au premier printemps partagé entre l'averse et le soleil d'une éclaircie (XI, 65), la vallée de la poitrine voit sa neige fondre (XI, 68). Ce cumul inhabituel de raretés a pour effet de magnifier le corps, mais peut-être, comme on dirait au $X V T^{e}$ siècle, de l'«étranger». Il est à peu près certain que l'Arioste s'amuse à ces comparaisons, qu'il ironise lui-même sur ses byperboles et sur les personnages passionnés qui s'y laissent prendre. On peut voir dans ces doubles célébrations comme deux mouvements inverses de séduction et de distanciation par lesquels se définit le maniérisme. Dans une étude ${ }^{24}$ que je me plais à rappeler ici et qu'on redécouvre sans une ride, Marcel Raymond caractérisait le maniérisme par l'ouverture de l'cuvre (rien de l'«architectonique classique»), par ce qu'il appelait les «allonges successives», par le souci de traiter la partie pour elle-même, séparée du tout. Selon lui, le maniérisme recherche le mouvement et allonge les formes; il pratique un art de la ligne et de la couleur étrange, un art dont le «caractère ornemental est souvent très marqué». Comme peintre $d u$ corps, l'Arioste transmet aux poètes français qui vont l'idolâtrer un béritage maniériste.

On compte par dizaines les imitations que les poètes français ont faites des portraits d'Alcine et d'Olympie. Laissons, pour la plupart, ces variantes insipides où elles se trouvent. Je me bornerai à quelques cas empruntés aux poètes de la Pléiade non sans rappeler que le blason «Du beau Tetin» n'aurait pas vu le jour sans l'Arioste. ${ }^{25}$ Marot, exilé, ne se trouvait-il pas à la cour de Ferrare peu après la parution de l'Orlando Furioso dans sa version définitive? Parmi les nombreuses variations que Ronsard a faites sur nos portraits, on trouve les trois principales dans la première ode publiée par le poète et adressée à Jacques Peletier du Mans, Des beautez qu'il voudroit en s'amie, le sonnet I6o des Amours, et la célèbre Elegie à Janet peintre du Roi. Cette dernière pièce peut se définir comme une vaste amplification d'"Alcine» et d'«Olympie», même si l'A rioste n'en est pas la source unique. En tout cas, le lecteur sera frappé par la multiplication des équivalences comparatives et métaphoriques. Ronsard veut à ce point donner à voir à son lecteur, par 
l'intermédiaire de Janet, c'est-à-dire à François Clouet, qu'il multiplie à l'excès ses bypotyposes. On en perd le sens de l'ordre comparatif et l'on se demande si les mille artifices de la nature sont les métaphores du corps de Cassandre ou si Cassandre elle-même devient métaphorique de la nature ou de l'art. Cette indistinction relève d'ailleurs bien du maniérisme, art de l'illusion et du trompe-l'cill. Arrêtons-nous au détail du sein:

\author{
Ainsi qu'en bosse eleve moi son sein, \\ Net, blanc, poly, large, profond \& plein. \\ Dedans lequel mile rameuses venes \\ De rouge sang tresaillent toutes plenes. \\ Puis quant au vif tu auras decouvers \\ Desous la peau les muscles \& les ners, \\ Enfle au dessus deux pommes nouvelettes \\ Come l'on voit deux pommes verdelettes \\ D'un orenger, qui encores du tout \\ Ne font qu'à l'heure à se rougir au bout.
}

(Les Meslanges, I 35-44)

L'Arioste est bien présent sous ce texte: variation sur l'équivalence picturale (élever le sein en bosse), allusion aux veines (mais ici pour les souligner), fameuses pommes d'Alcine. Pourtant Ronsard dépasse (outrepasse?) son modèle en faisant des pouvoirs du peintre et du poète le véritable objet de son élégie. Il met ici Clouet dans l'embarras, car il le pousse aux limites de son art, voire au-delà. On ne saurait peindre à la fois l'extérieur d'un sein et son anatomie interne, on ne saurait marquer les veines en bleu et tracer en rouge le sang qui les parcourt. Seul, le poète peut être à la fois Zeuxis et Vésale et désirer la totalité, quitte à faire de Cassandre un monstre. En tout cas, la distance prise par l'Arioste dans ses portraits atteint ici sa dimension extrême. On préférera le sonnet 160 des Amours, ${ }^{26}$ qui peut s'interpréter comme une recréation maîtrisée de nos portraits et une adbésion - sans distance, cette fois-ci - à la beauté du corps.

Du Bellay reprend nos portraits dans le sonnet 7 I de L'Olive. C'est un texte extrême en ce qu'aucune partie du corps n'y est nommée comme telle. N'était le vers I2 qui parle des «beautez. de Madame», un lecteur non averti, tombant par hasard sur ces vers, n'en comprendrait pas le sens. Comme dans l'Elegie à Janet, la topique du portrait atteint ses limites puisque l'usage métaphorique s'impose comme un absolu. Du Bellay renchérit sur le modèle, ce qui est le propre du maniérisme. Le sonnet en acquiert de la grandeur, je ne sais quel pouvoir oraculaire, un dire mallarméen qui place le corps féminin dans un ailleurs préservé: 
Le crespe honneur de cet or blondissant

Sur cet argent uny de tous coutez,

Sur deux soleilz deux petiz arcz voutez,

Deux petiz brins de coral rougissant,

[...]

Ce val d'albastre, \& ces coutaux d'ivoire,

Qui vont ainsi comme les flotz de Loire

Au lent soupir d'un zephire adoulci,

C'est le moins beau des beautez de Madame,

Mieulx engravée au marbre de mon ame,

Que sur mon front n'en est peinct le soucy.

(L'Olive 7I, I-4, 9-I4)

On voit aussi que Du Bellay soumet la sensualité à l'image spirituelle gravée dans son âme. C'est une autre façon de prendre ses distances.

Avec Pontus de Tyard, les portraits d'Alcine et d'Olympie connaissent un avatar des plus fins. Le Chant à son leut a paru, en I55s, dans le Livre de vers lyriques. C'est un poème en tierce rime de dix-buit tercets et un quatrain. Regardons les dix-neuf derniers vers:

Chante le droit, chante le gauche Pole:

Chante le pur de la voye lactée,

D'où le penser seulement me console.

Chante la main doctement usitée

A te sonner: admirable à escrire

L'invention du rare esprit dictée.

Ne chante point ce que je n'ose dire:

Tout ce parfait, que l'honnesteté cele,

Que craintif j’aime, et sans espoir desire.

Mais chante moy celle essence immortelle,

Qui, pour tenter du Ciel nouvelle trace,

Son æsle empenne, et son vol renouvelle.

Chante combien celle divine grace

Gaigne sur moy, et scet vivement peindre

L'amour au cœur, et le dueil en la face.

Si tu ne peux à la louange atteindre,

Que la beauté merite de ma dame,

Vueilles au moins si doucement te pleindre,

Qu'elle ait pitié (triste Leut) de ma flame.

(Livre de vers lyriques, Chant à son leut 40-58)

Avec beaucoup d'art, Pontus de Tyard donne une forme intéressante à la célébration du corps féminin. Une partie de celui-ci est réservée à chaque tercet: 
les cheveux, le front, le teint, etc. Et chaque tercet commence, anaphoriquement, par l'impératif Chante, c'est-à-dire, par une invitation du poète à son luth. Cette configuration a le double avantage de la régularité (aucune asymétrie dans l'évocation du corps) et de la disposition aérée, où les charmes ne s'entassent pas dans une série d'asyndètes. De manière variable, ces tercets incluent, après la description, une mention personnelle: ce front "Où la Vertu ... / ... de l'aimer me poind et admonneste», ces oreilles «Closes au mal, et non jamais fermées / Aux saints propos des celestes merveilles». Poìte néoplatonicien, Tyard sublime la sensualité de l'Arioste d'une manière très remarquable: la gorge de lait, s'inscrivant dans le cosmos, devient la Voie lactée et figure ainsi la pureté céleste (v. 40-42). Si, une seule fois, Tyard déroge à la régularité de l'anaphore, c'est pour évoquer les pudenda avec retenue, une sobriété presque gnomique et sans doute de la sincérité: toutes qualités inégalement répandues dans ce siècle foisonnant $(v .46-48)$. Le quatrain final inspirerait un commentaire de même nature.

Baif et Belleau ont une relation plus simple au texte de l'Arioste. Les portraits leur inspirent un développement heureux comme ces deux strophes de Baïf, où la répétition du même vise un effet de raffinement et de rareté:

Ta belle gorge polie

Est d'albastre rebondi,

Et ta poitrine jolie

D'albastre en large arondi:

Deux pommes d'albastre blanc

Au desus tiennent leur ranc.

Dou ces braz en long s'etandent

Comme deux souples rameaux,

Qui vers le fin bout se fendent

En cinq rameletz nouveaux,

Qui encor sonot finissans

En cinq roses fleurissans.

(Les Amours [de Meline] II 5)

Ces bras qui s'allongent et se prolongent en doigts et en ongles ne sont pas loin de rappeler le célèbre autoportrait du Parmigianino, où la main, reflétée par un miroir convexe, apparaît démesurément grandie.

Belleau accommode en prose les portraits d'Alcine et d'Olympie. Voici un extrait de sa Bergerie:

Plus je vous diray que le lait caillotté sur la jonchee n'a le teint si frais ne si douillet que sa gorge, elle est longuette, grassette, \& marquee de deux petis plis sous le menton, elle est si blanche que rien ne le peut estre plus, \& semble qu'Amour l'ait 
choisie pour luy servir de colonne pour pandre les dépouilles qu'il va butinant sur les hommes. Cette gorge finist en un sein large, blanchissant, sans monstrer ny muscle, ny jointure, ny aparance d'os. Ce beau sein siege de la chasteté, se renfle en deux petites montagnettes taillees à demi-bosse, abouties d'une petite fraizette rougissante au milieu, tirant $\&$ repoussant ses soupirs d'une juste cadance, ainsi qu'on voit les petis flots sur la greve de la mer, se renfler \& s'estendre sous la contrainte d'un petit vent mollet. $^{27}$

Le tableau des beautés corporelles apparaît comme renouvelé. Mieux que les vers, la prose permet le déroulement narratif et une cadence élargie qui donne à l'objet décrit toute son ampleur. Avec Belleau, le corps est raconté, selon l'habitude, dans tous ses détails maniéristes, mais il est comme inséré dans une vaste danse où alternent binaire et ternaire (binaire, par exemple: "I si frais ne ${ }^{2}$ si douillet», ternaire, par exemple: "' en un sein large, ${ }^{2}$ blanchissant, ${ }^{3}$ sans monstrer ${ }^{a}$ ny muscle, ${ }^{b}$ ny jointure, 'ny aparance d'os»; le troisième élément ternaire devient à son tour ternaire, etc.). Comme l'Arioste faisait alterner ses bourdes, Belleau joue des deux registres de son prosimètre; après Lemaire de Belges, il fonde le poème en prose du corps.

\section{L'Arioste inspire des imitations variées}

L'attrait de l'cuvre de l'Arioste, plus vaste que celle de Bembo, ne se limite pas à la liberté et à l'invention dont il fait preuve en matière de récit, d'imaginaire amoureux ou de portrait sensuel. Dans son beau livre, ${ }^{28}$ au ton juste, Alexandre Cioranescu a peut-être un peu vite négligé certains des nombreux rapprochements qu'Alice Cameron a soigneusement découverts. ${ }^{29}$ Ils ne sont pas tous probants, certains présentent une superficie vraiment réduite, mais beaucoup peuvent légitimement retenir l'attention. La mémoire que les poètes de la Pléiade ont des textes les mène dans des champs sémantiques très variés. On ne cherchera pas ici un examen exhaustif des emprunts. On trouve d'abord les topoi comparatifs: la jeune fille qu'un rival arrache à son amoureux ressemble à la rose intacte quand elle est sur pied, mais qui se flétrit quand on vient la cueillir. ${ }^{30}$ Quant à la comparaison de la jeune fille avec une rose non encore éclose, Belleau l'emprunte en partie à un madrigal de l'Arioste. ${ }^{3 \mathrm{I}}$ L'assimilation de la déraison amoureuse à la démesure d'Icare est reprise deux fois. ${ }^{32}$ Le combat entre les hirondelles et les abeilles figure le trouble profond de l'amoureux. ${ }^{33}$ Le contraste entre la présence favorable et l'absence bostile de l'aimée est rendu sensible par la comparaison construite sur le cycle du soleil. Même si Pétrarque a rassemblé quelques éléments de ce rapprochement, l'Arioste en est le véritable créateur. ${ }^{34}$ 
Comme Bembo, l'Arioste suggère des tableaux maniéristes que l'on chercherait vainement chez. Pétrarque: les mouvement des combattants comme donnés à voir par la comparaison des blés agités sous le vent printanier; ${ }^{35}$ le sang versé comparé à la pourpre rougissant le doigt de la brodeuse; ${ }^{36}$ la grotte où se cache la femme désirée; ${ }^{37}$ la nuit, complice de l'amoureux en bonne fortune. ${ }^{38}$ Signalons aussi le topos de Nature brisant son moule ${ }^{39}$ et celui du «sodalitium» (pour reprendre un terme de Lucien Febvre), c'est-à-dire ces amis poètes que l'on retrouve après une longue absence. ${ }^{40}$ Quant aux déclarations que Bradamante adresse à Roger sur sa fidélité absolue, elles requièrent maintes fois l'attention des poètes de la Pléiade. ${ }^{4 \mathrm{I}}$ On n'oubliera pas enfin que Baïf, reprenant le travail de Mellin de Saint-Gelais, a paraphrasé les chants IV (à partir de 5I), V et VI (jusqu'à Iб) de l'Orlando Furioso dans un poème intitulé La Genevre ${ }^{42}$ et que, sans collaboration, il a paraphrasé, du même Orlando, les stances 26 à 60 du chant XXV sous le titre de Fleurdepine. ${ }^{43}$

\section{Les Azolains éclairent-ils la composition des recueils français?}

Après avoir essayé d'inscrire dans une configuration générale une foule d'emprunts faits à Bembo ou à l'Arioste par la Pléiade, il n'est pas interdit de se poser une question plus générale et comme telle plus risquée: la composition des "canzonieri" français a-t-elle été influencée par les poètes italiens que nous étudions? Pensons particulièrement à L'Olive, aux Amours de Ronsard et à L'Amour de Francine. Le grand parangon est évidemment le Canzoniere de Pétrarque. Ce recueil concilie à la fois la variété et ce qu'on peut appeler un «telos» précis: la progressive assomption de Laure au ciel et sa finale assimilation à la Vierge. Une force organisatrice détermine le devenir de l'amoureux et son salut. D'une manière peut-être moins évidente, L'Olive prend tout son sens par les sonnets spirituels (chrétiens ou néo-platoniciens) de la fin. Les Amours de Ronsard, et par conséquent L'Amour de Francine qui les imite de très près, livrent moins facilement le secret de leur composition. Plusieurs critiques ont essayé de le percer, mais ils n'ont apporté que des réponses partielles; je pense à Michel Dassonville, ${ }^{44} \mathrm{~J} .-\mathrm{ClM}$ Moisan, ${ }^{45} \mathrm{R}$. Mélançon $^{46}$ et moi-même dans mes notes littéraires de l'édition de Livre de poche. ${ }^{47}$ Ronsard et Baïf étaient pénétrés de l'Orlando Furioso. Quand le soupirant des Amours rêve d'une totale liberté sylvestre: "Et pourquoy, Cieulx, l'arrest de vos destins / Ne m'a fait naistre un de ces Paladins / Qui seulz. portoyent en crope les pucelles?» (Les Amours II7), il pense aux paladins de l'Amadis et de l'Orlando. La composition de ce dernier poème illustre une esthétique de la rupture et de la variété en mouvement. Au temps de sa jeunesse, c'est-à-dire quand l'Orlando Furioso l'enchantait sans réserve, 
Ronsard a certainement apprécié ces discordances entre les aventures successives. Lui et Baïf en ont tiré une justification supplémentaire de leur composition «à sauts et à gambades» (pour user d'une métaphore de Montaigne qui est pratique ici).

Bembo pourrait conférer à cette variété, si authentiquement maniériste, un sens plus spécifique, et de nature dialogique. Il y a bien longtemps qu'on ne prend plus les poèmes des Amours pour des billets doux envoyés à Cassandre Salviati, devenue Dame de Pray, par son soupirant Ronsard; pas plus qu'on ne considère le recueil comme le journal d'une passion. Ce qui rend impossible une telle lecture, ce sont d'abord les incohérences chronologiques, les changements de nom, mais surtout la visée amoureuse. Dans la réalité d'une seule et même conquête, comment peut-on encenser en même temps la femme aimée pour sa vertu chaste, se plaindre jusqu'à la mandire de ses résistances, la considérer comme le miroir de la beauté, comme une partie détachée du monde idéal et en même temps désirer la posséder avec une sensualité d'une rare vigueur? Seule l'explication par l'imaginaire permet d'intégrer ces contradictions. Le mauvais romancier écrit ses romans à partir de sa vie réelle, le grand romancier à partir de tous les événements de ses vies possibles, a dit un auteur dont j'ai oublié le nom. Nous sommes tous traversés de fantasmes contradictoires, le poète en premier. Et il les exprime en s'accordant ainsi au style d'une époque de grands changements qui a fait de la variété et de brusques retournements la traduction du mouvement qui l'anime. Mais Bembo permet, sinon d'ordonner un mouvement qui n'a de raison d'être que lui-même, du moins de l'intégrer dans un échange dialogique. Des célèbres ouvrages latins ou italiens où s'expose le plus souvent très largement une théorie amoureuse (ceux de Ficino, Equicola, Colonna, Castiglione, Leone Hebreo), les Asolani sont les seuls à offrir à la fois un dialogue et une typologie des attitudes passionnelles nettement clarifiée. Rappelons qu'au château d'Asolo, à l'occasion d'une fête, un dialogue sur l'amour se tient entre trois jeunes gens bien nés que Bembo présente sous le nom de Perottino, Gismondo et Lavinello. Trois jeunes filles participent à la joute oratoire, très discrètement. Les positions sont présentées de manière unitaire et à vrai dire plutôt monologique. A Perottino, le livre $I^{e r}$, pour mandire l'amour et étaler sa mélancolie; il représente bien l'amoureux pétrarquiste malheureux. La cruauté de la femme, pense-t-il, ou le malheur engendré par la mauvaise fortune inflige à l'amour des tourments sans fin. $\grave{A}$ Gismondo, le livre II, pour louer un amour plus sensuel que spirituel, de nature épicurienne. Si Perottino ne retenait de la passion que les éléments négatifs, Gismondo en isole tous les aspects euphoriques. Quand deux êtres, marqués par le manque, se retrouvent, ils éprouvent une complétude parfaite (on devine l'androgyne), car la nature commande leur raison et ne leur inspire que des désirs honnêtes. Les sens ont la plus grande part à cet amour dont Gismondo 
souligne le caractère civilisateur (peuplement du monde et progrès de la civilisation). Le regard joue un rôle primordial; il s'enchante des beautés physiques de la belle, transperce les habits pour deviner la beauté d'un sein par exemple (dans la description des petites pommes érotiques, Bembo ne le cède point à l'Arioste). Quant à l'esprit, il nourrit l'imaginaire, voué souvent à la représentation intérieure de ce que la pudeur cache. Toutes les chansons de Gismondo ont pour cadre un locus amœnus, comme celles de Perottino se situaient dans un locus horribilis. À Lavinello et à l'ermite qu'il rencontre, le livre III (et c'est ici que la position dialogique apparaît vraiment) pour critiquer l'insuffisance des positions de Perottino et de Gismondo et pour présenter une vision sereine, sublimée de l'amour. Lavinello, corrigé par l'ermite qu'il rencontre, transcende les conceptions de ses deux interlocuteurs. C'est le premier moteur qui a insufflé la raison dans notre cour. Si donc elle domine, on évitera l'amour trop sensuel aussi bien que l'amour malbeureux. Étant inscrit dans la permanence de l'être, le vrai amour ne connaît pas la satiété du désir. Quant à la nature, elle n'est pas l'antagoniste de l'élévation. En nous dévoilant le ciel extérieur, sa beauté, son organisation, elle sollicite notre libre arbitre et le conduit ainsi à reconnaître la beauté supérieure, à la rechercher et à en faire l'objet de sa quête. L'amour de la beauté féminine doit nous porter à un objet plus élevé qui est le ciel invisible.

Ronsard, comme Baïf et les autres poètes de la Pléiade, connaissaient les Asolani. Comment pourrait-on s'en étonner? Au moins trois emprunts jamais signalés - l'attestent chez Ronsard. ${ }^{48} U n$ canzoniere pétrarquiste est toujours parsemé d'apostrophes: à la belle courtisée, au dien Amour, à la nature, du poète à lui-même, etc. Ces apostrophes variées sont l'ébauche d'un dialogue. ${ }^{49}$ Pourraient-elles en être le reflet? Si, dans Les Amours (et les remarques valent aussi pour L'Amour de Francine), les postulations se révèlent beaucoup plus variées, beaucoup plus bétérogènes que dans L'Olive ou Les Erreurs amoureuses (les deux canzonieri qui ont précédé celui de Ronsard), si elles rendent plus difficile la comprébension d'un ensemble, ne sont-elles pas autorisées, aux yeux du poète, parce qu'elles reprennent les postulations de Perottino, de Gismondo et de Lavinello? Le "je" du poète est tour à tour l'un des trois personnages des Asolani. Ce grand dialogue en trois livres sur l'amour typifie les conduites amoureuses et assure ainsi une certaine unité de propos. Nous pourrions donc comprendre l'ensemble des Amours comme une fugue à trois voix. C'est l'amoureux Perottino qui parle - après bien d'autres, dont Pétrarque - quand le poète regrette sa liberté depuis le jour où il s'est laissé tourmenter sans espoir (s. I4); c'est lui aussi qui se lamente dans la forêt de Gastine et «sanglote une pleinte» à faire «gemir le plus dur des rochers» (s. 93). C'est l'amoureux Perottino qui accuse fortement sa Dame de mépriser la loi amoureuse et de renier faussement sa foi (s. II \&), c'est Perottino 
encore qui, dans une plainte vive, somme celle qui lui a volé son cour de le lui rendre (s. I64). Quand l'amoureux Ronsard sanglote et se lamente, "Pale, agité des flotr. de la tourmente» et supplie son ami Du Bellay d'être attentif à son sort malheureux, n'emprunte-t-il pas ses accents désespérés au devisant malheureux des Azolains (s. 45)? Dans le dédale des Amours, il n'est pas difficile de repérer un amoureux Gismondo. C'est celui qui soubaite «r'avoyr entre ses bras» les beautés qui l'ont ému: un «doulx parler», des «cheveulx d'or», des «coustaulx plantureux» (c'est-à-dire, selon Muret, des épaules et une poitrine, s. 46). C'est celui qui demande à Vénus de pouvoir sans mourir «soustenir le doulx combat» tout proche (s. 100), qui salue le coin, c'est-à-dire l'endroit, où il a pu dévoiler son tourment amoureux aux oreilles enfin complaisantes de sa belle (s. 99) et le coin pourrait bien être cette «chambrette beureuse» où «deux heureux flambeaux, [lui] font escorte apres si longue peine» (s. I02). Quant au Ronsard Lavinello, nous l'avons rencontré dans le sonnet présenté au début de cette étude (s. ITI), nous le rencontrerions dans l'action de grâces du s. I74, où le poète remercie «l'beureux trait» des yeux de la belle qui a permis à sa pensée de se couvrir d'ailes pour adorer le «vray beau». Pensons aussi à cet ordre compliqué donné par le poète à son ami le peintre Denisot: voler au ciel, y contempler les divinités d'un xil d'Argus, imaginer à partir d'elles un patron, puis redescendre pour peindre Cassandre sur ce modèle avec le teint de mille fleurs trempées dans les pleurs du poète (s. $I 06)$.

Les trois devisants de Bembo représentent des pôles identifiables dans Les Amours, mais le poète navigue souvent d'un pôle à l'autre et introduit ainsi le mouvement. Je ne prendrai pour preuve que le fameux sonnet du nombril (s. 67). Ce blason nous élève, comme Lavinello, vers le signe divin de l'Androgyne («signe divin, qui divinement ore / Retiens encore l'Androgyne lien»), mais nous convie, non sans ironie, je pense, à l'admiration lascive, puisque le nombril conduit au «paradis» où «le plaisir se niche». Nous voici dans le monde de Gismondo. Ce ne sont pas des sources qui viennent d'être présentées ici, répétons-le. Bembo et ses Asolani ne se substituent nullement aux nombreux poètes imités parmi lesquels Pétrarque tient le premier rang. Simplement, les attitudes amoureuses, le comportement et les conceptions du "je" ronsardien, si déroutants dans leur rupture, pourraient s'incarner dans des personnages qui subsument leur extrême diversité. Les Asolani fourniraient aisément les points de fixation d'un réseau organisateur qui permet de donner plus de sens à la variété ronsardienne.

Il est temps de conclure. Bembo et l'Arioste nourrissent la Pléiade en sa jeunesse, c'est-à-dire entre I550 et I560. Après ce temps, les poètes de cette école prennent leurs distances avec leurs modèles. Ronsard est à cet égard exemplaire. Dans l'épître Au lecteur placée en tête de La Franciade (I572), il 
recommande au poète épique de ne pas imiter l'bistorien, asservi à la succession chronologique. Pourtant, la liberté ne permet pas, dit-il, d'imaginer «une Poësie fantastique comme celle de l'Arioste, de laquelle les membres sont aucunement beaux, ${ }^{50}$ mais le corps est tellement contrefaict \& monstrueux qu'il ressemble mieux aux resveries d'un malade de fievre continue qu'aux inventions d'un bomme bien sain». ${ }^{\text {I }}$ Ce n'est plus la voix $d u$ bouillant amoureux des premières années qu'on entend ici, mais celle du poète classicisant, celui auquel Pasquier reproche un peu trop catégoriquement d'avoir «chastr[é] son livre de plusieurs belles et gaillardes inventions». ${ }^{22}$ Quant à Bembo, délaissé depuis I560, Ronsard lui emprunte, en I578, une invective contre le mariage, privilège des sots, et un éloge de l'amour libre. ${ }^{3}$ Mais Bembo s'amusait dans des stances carnavalesques, alors que Ronsard s'irritait sérieusement de la pruderie d'Hélène et de l'bypocrisie de la cour. Nous sommes décidément très loin de l'empyrée néo-platonicien.

\section{André Gendre}

\section{Bibliographie des éditions utilisées:}

Lodovico Ariosto, Orlando furioso, a cura di L. Caretti, Torino, Einaudi, i 966.

Lodovico Ariosto, Tutte le opere, a cura di C. Segre, vol. III: Liriche latine, Rime, Satire, Milano, A. Mondadori, I964.

Pietro Bembo, Prose e rime, a cura di Carlo Dionisotti, Torino, UTET, i 966.

Jean-Antoine de Bä̈ғ, Les Amours [de Meline], édition par M. Augé-Chiquet, Paris, Hachette, I 909 .

Jean-Antoine de Baïf, Les Amours de Francine [en fait: L'Amour de Francine], édition par E. Caldarini, Genève, Droz, I 966 et 1967, 2 tomes.

Jean-Antoine de Bä̈ғ, Diverses Amours de J.-A.. de Baïf, dans: CEuvres en rime, édition par Ch. Marty-Laveaux, t. I, Paris, Lemerre, i 88 I, reprint Slatkine, I965. Jean-Antoine de Bä̈ғ, CEuvres complètes. Première partie: Neuf Livres des Poemes, édition sous la direction de J. Vignes, Paris, Champion, 2002.

Remy Belleau, Eurres poétiques, édition sous la direction de Ge. Demerson, Paris, Champion, 1995-2003, 5 tomes parus.

Joachim Du Bellay, Euvres poétiques, édition par H. Chamard, puis par G. Demerson, Paris, Société des Textes Français Modernes, I908-1985, 8 tomes.

Pierre de Ronsard, CEuvres complètes, édition par P. Laumonier, Paris, Société des Textes Français Modernes, I9I4-1975, 20 tomes en 25 vol. (Les Amours, sans autre mention, se trouvent au tome IV, Les Amours, avec mention "I553", au tome V, Les Meslanges, au tome VI, Les Continuations, au tome VII et les Sonets puor Helene, au tome XVII).

Pontus de Tyard, Euvres poétiques complètes, édition par J. C. Lapp, Paris, Société des Textes Français Modernes, I 966. 


\section{La Pléiade entre Bembo et l’Arioste}

Le sigle > marque un emprunt d'un poète de la Pléiade à Bembo ou à l'Arioste. Comme la numérotation des poèmes de l'Arioste peut varier suivant les éditions, les incipit seront donnés.

i. Bembo, Rime 7, v. 5-8 > Ronsard, Les Amours i 35, v. 5-8, t. IV, p. I 3 I et Bä̈F, L'Amour de Francine III, 8, v. 33-56, t. II, p. 27-28; BЕмво, Rime I9, v. 3-4 et 20, v. $7>$ Ronsard, Les Amours 2, v. I 2-I 4, t. IV, p. 7; BЕмво, Rime $20>$ BAÏF, L'Amour de Francine I, 40, t. I, p. 49; Bembo, Rime 28, v. I-4 > Ronsard, Les Amours 83, v. 5-8, t. IV, p. 84; Bembo, Rime $29>$ Bä̈F, L'Amour de Francine I, 20, t. I, p. 26; BЕмво, Rime 45, v. 5-I4 > BÄ̈F, L'Amour de Francine I, 6, v. I-4 et 9-I I, t. I, p. 7; BЕмBo, Rime 46, v. I-2 et 9-I I > Ronsard, Les Amours I I 8, v. 4 et 9-I I, t. IV, p. i I 5-i6; Bembo, Rime $54>$ Ronsard, Les Amours 85 , v. i-8, t. IV,

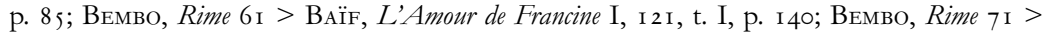
BAї̈, L'Amour de Francine I, 7, t. I, p. 8; BЕмво, Rime $92>$ BAїғ, L'Amour de Francine I, I, t. I, p. I (thème renaissant, plutôt que pétrarquiste, de l'immortalité poétique); BEmBo, Rime Ios > Bä̈f, L'Amour de Francine II, 3, t. I, p. I45; Bembo, Rime I 33, v. I-4 > Ronsard, Les Amours 7i, v. 5-8, t. IV, p. 72-73; Bемво, Rime I 33, v. I-9 > Ronsard, Les Amours I42, v. 9-I 4, t. IV, p. I 37-38; Вемво, Rime I 33, v. I 2-I 4 > Ronsard, Les Amours 5 5, v. 9-I I, t. IV, p. 57. Arioste, Rime i4, La rete $f u>$ Du Bellay, L'Olive io, t. I, p. 35, Tyard, Erreurs amoureuses, I, 26, p. 39, Ronsard, Le Bocage (I 550), 3, v. 2 I-25, t. II, p. I64, Belleau, La Bergerie, II, xv-I 5, t. IV, p. 220; Arioste, Rime I6, Ben che 'l martir > Ronsard, Les Amours 7, t. IV, p. I I-I 2 et La Continuation 33, t. VII, p. I 5 o; Arioste, Rime 27, Quando muovo > BÄ̈F, L'Amour de Francine III, I7, v. I7-24, t. II, p. 48; ARIOsTE, Rime, Oh se, quanto è l'ardore > BAÏF, L'Amour de Francine II, 25, t. I, p. I7I; Arioste, Orlando Furioso XxiII, I 25 -I $27>$ Du Bellay, L'Olive 25, t. I, p. 48-49, L'Olive 42, t. I, p. 62-63, BaÏF, L'Amour de Francine I, 48, t. I, p. 58, Ronsard, Amours d'Eurymédon et de Callirée, Chanson par stances, v. I 3-i6, t. XVII, p. i64; Arioste, Orlando Furioso xxxini, 63-64 > Du Bellay, L'Olive, 47, t. I, p. 66-67.

2. Voir, entre autres, Pétrarque, Rvf. I73, 205 et 35 I, etc. et Serafino, Se amor tanto amar, éd. Menghini, p. 209.

3. Citons quelques lignes du fameux commentaire de VArchi (Lezzioni, Firenze, F. Giunti, I 590, p. 285 ): «Quel che per se, e separatamente, ò fosse il dolce, ò fosse l'amaro v'ancideria. V'anciderebbe, modo proprio provenzale, e del verso (come n'insegna il medesimo autore nelle sue divine prose) v'aita, cioè essendo cosi mescolato, e confuso col suo contrario, e scemato in parte di sua virtù, v'aita, e v'arreca scampo e salute. Ne ci debbano parere nuovi \& inusitati questi miracoli d'Amore, iquali noi tutto il giorno non pure udiamo, \& leggiamo, ma eziandio proviamo, e sentiamo».

4. Cette belle comparaison finira par connaître l'avatar parodique que lui réserve Thomas Diafoirus.

5. Commentaire de Muret à propos du v. 2: «De l'Idée qu'il en avoit eternellement conceüe».

6. À propos du trait d'Amour, Bembo a fourni à Ronsard l'image précise de la pénétration vasculaire de la passion. Bembo, Rime io, v. 5-8 > Ronsard, Les Amours i 30, v. 5-8, t. IV, p. I 26. Cet emprunt n’a jamais été signalé.

7. Ronsard a employé cet adjectif dans le sonnet 52 du premier livre des Sonets pour Helene, STFM, XVII, p. 243, v. I I.

8. Voir la note I.

9. Ariosto, Rime i4 > Du Bellay, L'Olive io, t. I, p. 35. 


\section{André Gendre}

io. Ariosto, Rime 7 > Du Bellay, L'Olive 5, t. I, p. 30-3 I.

i i. Ariosto, Rime is > Du Bellay, L'Olive 8, t. I, p. 33.

i 2. Ariosto, Rime i6 > Du Bellay, L'Olive 30, t. I, p. 52-53.

I 3. S. Freud, Gesammelte Werke, vol. 7, p. 2 I 3 sqq., traduit en français par La création littéraire et le rêve éveillé dans Essais de psychanalyse appliquée, Paris, Gallimard, I933, p. 69-82.

I4. Mais la sensualité ou l'érotisme de l'Arioste sont le plus souvent discrets, comme le montre très bien P. Larivaille, dans une livraison antérieure de notre revue: De l'équivoque érotique dans la poésie italienne de la Renaissance, et de l'érotisme discret de l'Arioste en particulier, «Italique», II (1999), p. 33-53. Dans la plupart des cas, ce sont les poètes de la Pléiade qui renchérissent sur ce point.

i 5. Arioste, Rime i 8, Aventuroso carcere soave, v. io et i 2: «ma parole sciolte [...] ma dolci baci,» > Du Bellay, L'Olive 33, v. I 2-I 3, t. I, p. 55 .

i 6. Du Bellay, XIII Sonnetz de l'Honneste Amour, 2, t. I, p. I 40. En revanche, le sonnet i 8 de L'Olive, t. I, p. 4I-42, est plus conforme au modèle de l'Arioste.

17. Signalons aussi les deux réécritures que Baiff a faites du «capitolo» Opiù che'lgiorno, Rime 66, de l'Arioste: Diverses Amours III, 4, v. 23-44, t. I, p. 373 (éloge des vertus érotiques de la nuit) et Diverses Amours III, 6, t. I, p. $380-86$ (éloge du lit).

I 8. Voir E. Caldarini, $\grave{A}$ propos du sonnet CVIII de Ronsard, «Bibliothèque d'Humanisme et Renaissance», XXVII (1965), p. 653-54.

I9. "Mais plus heureux [en supposant que l'on ait traduit la série des felice par beureux] celui qui recevra vie de ce soleil, dont la belle lumière ôte à la mort son amertume, car l'un rassasie de joie et l'autre n'a plus guère de venin".

20. Clément Marot, Euvres poétiques complètes, Paris, Bordas, i 993, t. II, p. 24I-42.

2. Voir G. Pozzi, Il ritratto della donna nella poesia d'iniżio Cinquecento e la pittura di Giorgione, «Lettere italiane», XXXI (1979), p. 3-30. Sur l'histoire du portrait, consulter aussi l'article très riche de R. Baehr, Das Porträt der Alcina in Ariosts Orlando furioso (VII, IO-IS), «Italienische Studien», Italienisches Kulturinstitut Wien, Heft I (1978), p. 5-I 7 .

22. Larivaille, De l'équivoque érotique cit., p. 50.

23. Pour l'importance du mouvement à la Renaissance, voir: J. Starobinski, Montaigne en mouvement, Paris, Gallimard, I993 ( ${ }^{\text {re }}$ éd., I982) et M. Jeanneret, Perpetuum mobile, Paris, Macula, I 997 .

24. M. Raymond, La Pléiade et le maniérisme, dans Lumières de la Pléiade, Paris, Vrin, ig66, p. 391-423, en part., p. 395-99. Étude reprise, sous le titre Ronsard et le maniérisme, dans: M. Raymond, Etre et dire, Neuchâtel, La Baconnière, I 970, p. 63-I I 2.

25. Ni probablement aussi sans la Gloria d'amore et la Pegasea d'Olimpio di Sassoferato.

26. «Ces flotz jumeaulx de laict bien espoissi, / Vont \& revont par leur blanche valée, / Comme à son bord la marine salée, / Qui lente va, lente revient aussi. / Une distance entre eulx se fait $[\ldots] »$. 


\section{La Pléiade entre Bembo et l’Arioste}

27. Remy Belleau, La Bergerie I, Paris, Champion, 200 I, t. II, p. 67.

28. A. Cioranescu, L'Arioste en France, des origines à la fin du XVIII siècle, Paris, Éd. des Presses modernes, I939, deux tomes en un vol.. Après soixante ans, il n'est pas impertinent de tenter une nouvelle évaluation.

29. A. Cameron, The Influence of Ariosto's Epic and Lyric Poetry on Ronsard and his Group, Baltimore, The Johns Hopkins Press, I 930. Pour mémoire, on peut mentionner les premières recherches sur le sujet: J. Vianey, L'Arioste et la Pléiade, «Bulletin italien», I (I9o I), p. 3 I 5-I 6 et, du même auteur, Le Pétrarquisme en France au XVI siècle, Montpellier, Coulet, I 909; voir en particulier, le chapitre I, section II et le chapitre II de cet ouvrage.

30. Arioste, Orlando Furioso I, 4I-44 > Bä̈F, Diverses Amours I, 22, t. I, p. 295-96.

3i. Arioste, Rime 54, La bella donna mia > Belleau, La Bergerie II, xv-I6, t. IV, p. 220-2 I.

32. Arioste, Orlando Furioso xxxir, 2 I > Du Bellay, L'Olive 37, t. I, p. 5 et Belleau, La Bergerie I, I 8, t. II, p. 63-64. Voir, éventuellement, RonsARD, Sonets et madrigals pour Astrée I, t. XVII, p. I79. Mais il ne faut pas oublier le sonnet de Sannazar (Rime 79): Icaro cadde, certainement antérieur à la stance d'Orlando Furioso.

33. Arioste, Orlando Furioso xxvi, i7 > Belleau, La Bergerie I, i 5 , t. II, p. 60.

34. Arioste, Orlando Furioso Xlv, $38>$ Du Bellay, L'Olive 3 I, t. I, p. 53, Divers Jeux rustiques I 7, v. 3 I-48, t. V, p. 48 et Ronsard, Les Amours i 65, t. IV, p. I 56-57.

35. Arioste, Orlando Furioso xvi, $68>$ Du Bellay, Recueil de poésie, Chant triumphal, v. 8 I-92, t. III, p. 79-80 et Ronsard., La Franciade II, v. 214-I6, t. XVI, p. I04.

36. Arioste, Orlando Furioso xxiv, 65-66 > Ronsard, Les Hymnes, Hymne de Pollux et de Castor, v. 698-704, t. VIII, p. 324 et Ronsard, La Franciade II, v. I405-10, t. XVI, p. I67.

37. Arioste, Orlando Furioso xxili, ioo-rog et Orlando Furioso i, 35 sqq. > Ronsard, Les Meslanges, Le Houx, v. 6 sqq., t. VI, p. I 38 sqq.

38. Arioste, Orlando Furioso xlv, $38>$ Belleau, Poemes nouvellement édités en I578, La Nuict, t. VI, p. 99-103.

39. Arioste, Orlando Furioso x, $84>$ Ronsard, Recueil des nouvelles Poésies, II, Compleinte à la Royne Mère du Roy, v. I 29-34, t. XII, p. I79, Élégies, Mascarades et Bergerie, Elegie à la Majesté de la Royne d'Angleterre, v. I-I 2, t. XIII, p. 39, Le Tombeau de Marguerite de France, v. 387-402, t. XVII, p. 82, Les Amours (I 578) II, Stances, v. I45-50, t. XVII, p. I 2 I-22.

40. Arioste, Orlando Furioso Xlvi, I-I7 > Ronsard, Bocage (I 550), A son retour de Gascogne, v. 9-40, t. II, p. 200-20I, Les Isles fortunées, v. 68 sqq., t. V, p. I78 sqq., Du Bellay, Les Regrets I 29, t. II, p. I 55-56.

41. Arioste, Orlando Furioso xliv, 6i-66 > Du Bellay, L'Olive 29, t. I, p. 5 I-52 et L'Olive 35, t. I, p. 56-57, BAÏF, Les Amours [de Meline] I, 32, p. 58-59, Ronsard, Les Amours, Chanson, v. 43 sqq., t. IV, p. I75-76, BAÏF, L'Amour de Francine II, I I 5, t. I, p. 275 et L'Amour de Francine IV, 7, v. 35-84, t. II, p. IO3-IO4 (longue imitation de la lettre de Bradamante).

42. Baїғ, Le Cinquieme Livre des Poemes 3, La Genevre, par Sangelais et Baï, p. 3 I 4 sqq.

43. Bä̈ғ, Le Cinquieme Livre des Poemes 4, Fleurdepine, p. 34I sqq. 
44. M. Dassonville, Pour une interprétation nouvelle des Amours de Ronsard, "Bibliothèque d'Humanisme et Renaissance», XXVIII (1966), p. 241-70.

45. J.-Cl. Moisan, L'Organisation des Amours de Cassandre, «Études littéraires», IV (1971), p. $175-86$.

46. R. Mélançon, Sur la structure des Amours (I552) de Ronsard, «Renaisssance and Reformations, Toronto, XIII (1977), p. I 19-35.

47. Pierre de Ronsard, Les Amours et Les Folastries (I552-Is60), Édition établie, présentée et annotée par A. Gendre, Paris, Librairie générale française, «Le Livre de poche classique», 1993, p. 459 sqq. Significativement, J. Rousset ne parle ni de Ronsard ni de Baif dans son fameux article: Les recueils de sonnets sont-ils composés?, dans The French Renaissance and its Heritage, essays presented to Alan Boase, London, Methuen et C ${ }^{\circ}$, 1968, p. $203^{-1} 5$.

48. I ${ }^{\circ}$ Bembo, Asolani I, 24, chanson de Perottino, v. 55-57: «Eco sola m'ascolta, e col mio pianto / agguagliando 'l suo duro antico stato, / meco si duol di sì penose notti» > Ronsard, Le Sixiesme Livre des Poëmes, Discours d'un amoureux desesperé, v. 226-28, t. XV, p. 94: «Echo sans plus de mes soupirs atainte / Me respondoit \& d'un pareil esmoy / M'accompagnant pleuroit avecques moy». $2^{\circ}$ Comme il a été constaté au début de cette étude, Ronsard emprunte au sonnet 38 de Bembo le sonnet i 7 I des Amours en s'écartant partiellement de son modèle au premier quatrain. Mais c'est Bembo encore qui cautionne cet écart. Ronsard compare le monde à un temple; il n'a pu trouver cette comparaison ni chez Dante ni chez Pétrarque. Seuls Sannazar (Rime roo, Scorto dal mio pensier, v. I33) et Вемво, Asolani III, I g: «questo sacro tempio, che noi mondo chiamiamo» pouvaient la lui fournir. Le contexte désigne sans conteste les Azolains comme source de la comparaison ronsardienne. $3^{\circ}$ Dans les Amours d'Eurymedon et de Callirée, l'amoureux pense que si Amour est peint avec des ailes, ce n'est pas parce qu'il est «leger ne vicieux», mais parce qu'il est «nay du ciel, pour retourner aux cieux» (Stances, v. 55-60, t. XVII, p. 146-47). Ronsard prend le contre-pied de Properce (II I 2, v. I-5), certes, mais avec l'aide de Bembo: «essi [i vostri scrittori] il fanno adorar dagli uomini e consacrangli altari e porgongli voti e dannogli l'ali da volare in cielo», Asolani I, I 2.

49. Voir F. Hallyn, L'apostrophe dans les Amours de Cassandre, dans Ronsard. Colloque de Neuchâtel, Neuchâtel, Faculté des lettres et Genève, Droz SA, I987, p. 25-40.

50. "Sont beaux d'une certaine manière".

5 I. T. XVI, p. 4. Dans une pièce posthume pour célébrer Bartolomeo Delbene, Ronsard fait l'impasse sur deux siècles de poésie italienne. Son destinataire, selon lui, émerge comme d'un désert, étant le premier poète qui compte après Pétrarque. Autant dire que Bembo et l'Arioste n'existent pas dans cette brève histoire de la poésie italienne. J. Balsamo, Note sur l'Élégie a Bartolomeo Delbene Florentin, «Revue des Amis de Ronsard», X (1997), p. I45-63, a bien montré que l'oubli de Ronsard comporte une bonne part d'ironie à l'adresse de Delbene. Il serait imprudent d'en tirer quelque conclusion à propos du présent sujet.

52. E. Pasquier, Les Recherches de la France, VII, 6, Paris, Champion, I996, t. II, p. I425.

53. Bembo, Rime, Stanze 36 > Ronsard, Sonets pour Helene II, 25 , t. XVII, p. 266-67. 